\title{
Is Post Operative Radiotherapy Justified for Completely Resected Locally Advanced Renal Cell Cancers?
}

\author{
Reham Abdulmoniem ${ }^{1,2}$, Tarek Haikal ${ }^{3}$, Hossam Darwiesh ${ }^{3}$ \\ ${ }^{1}$ Radiation Oncology Department, National Cancer Institute, Cairo University, Cairo, Egypt; ${ }^{2}$ Comprehensive Cancer Center, King \\ Fahad Medical City, Riyadh, Saudi Arabia; ${ }^{3}$ Medical Oncology Department, Damietta Cancer Institute, Ministry of Health, Damietta, \\ Egypt. \\ Email: dr.reham71@hotmail.com
}

Received September $9^{\text {th }}, 2013$; revised October $8^{\text {th }}, 2013$; accepted October $16^{\text {th }}, 2013$

Copyright (C) 2013 Reham Abdulmoniem et al. This is an open access article distributed under the Creative Commons Attribution License, which permits unrestricted use, distribution, and reproduction in any medium, provided the original work is properly cited.

\begin{abstract}
Background: There is an underutilization of postoperative radiation therapy (PORT) in renal cell carcinoma (RCC) following radical nephrectomy $(\mathrm{RN})$. The main reason for that is the lack of strong evidence and the contradictory data in the literature regarding its benefit. We aimed to evaluate the efficacy of PORT in locally advanced patients with RCC following complete resection. Materials and Methods: The patients had RN and at least two of the poor prognostic factors like lymph nodes involvement $(\mathrm{LN}+)$, renal vein invasion (RVI), inferior vena cava invasion (IVCI) and renal capsule infiltration (RCI) were included in the study. Ninety-four patients were retrospectively evaluated; 56 patient received PORT 50Gy/25 fractions $/ 5$ weeks and 38 patients who did not receive PORT were compared. The LN+, RVI, IVCI and RCI were documented in 63 (67\%), 46 (49\%), 30 (32\%) and 71 (76\%) patients respectively. Results: Eight patients (14\%) in PORT arm developed local recurrence (LR) are compared with 10 patients (26\%) for non-PORT arm. Five-year overall survival (OS) rates were 78\% and 70\% for PORT and non-PORT arms respectively ( $\mathrm{p}=0.3)$, while 5year locoregional control (LRC) rates were $88 \%$ for PORT arm and $70 \%$ for the non-PORT arm $(\mathrm{p}=0.05)$. The IVCI and $\mathrm{LN}+$ affected OS significantly (p values 0.007 and 0.009 ) respectively. The RCI and LN+ only affected the LRC with $p$ values $0.03,0.04$ respectively. Two out of 56 patients $(3.5 \%)$ received PORT developed intestinal obstruction which was treated surgically. Conclusion: The PORT decreased the LR rate in high risk locally advanced RCC patients significantly. The high incidence of distant metastasis offsets this improvement at the level of overall survival.
\end{abstract}

Keywords: Renal Cell Carcinoma; Locally Advanced; Postoperative Radiation Therapy; Outcomes

\section{Introduction}

The incidence of RCC, which accounts for $3 \%$ of all adult malignancies, is gradually increasing and considered as the most lethal carcinoma of the genitourinary tumors, with $>40 \%$ of patients dying from their tumor $[1,2]$. Seventy percent of patients presented by locally advanced disease are still potentially curable by RN; however, LR rate is high for such group of patients $[3,4]$. The lymph node involvement, renal capsule invasion, renal vein involvement and inferior venal cava thrombosis are well-known bad prognostic indicators specially if the patients had 2 or more of these factors $[5,6]$. Some retrospective studies showed survival benefit for adjuvant post-operative radiation therapy [7-10]. However, this has not been confirmed in prospective randomized trials, mostly because these trials were performed during the era of conventional irradiation using old radiotherapy techniques $[11,12]$. Theoretically, PORT would improve the local control in patients with high-risk features. The use of targeted therapy following $\mathrm{RN}$ as adjuvant treatment had improved the survival, and hence the local recurrence became a real problem especially in patients with high risk features for local recurrence.

The purpose of the present study was to evaluate the value of post-operative radiotherapy on local control and survival in high risk RCC patients for local recurrence following $\mathrm{RN}$.

\section{Materials and Methods}

\subsection{Inclusion Criteria}

The medical records of 230 patients with RCC treated at Damietta Cancer Institute (DCI) from 1998 to 2006 were 
reviewed. One hundred thirty six patients were excluded for the following reasons: incomplete hospital records, early stage disease, second malignancy, incomplete resection and distant metastasis at diagnosis.

High risk patient for local recurrence were only selected for analysis. High risk patients were defined as patients with stage III or IV and having two factors of following of poor prognostic factors; 1) lymph node involvement, 2) renal capsule invasion, 3) renal vein involvement and 4) inferior venal cava thrombosis. Total 94 patients met the criteria and were evaluated for the purpose of this study.

\subsection{Radiation Therapy Details}

The PORT patients were treated as per Institutional protocol. The patients treated in supine position using vertical, transverse and lateral laser beams for alignment. All patients were simulated using Philips AcQsim RT CTSimulator, with multiple slices taken. The target volume was limited to the renal bed and para-aortic lymph nodes. The radiation was delivered with anteroposterior/posteroanterior portals to a total dose of 50.4 Gy with a daily fraction of $1.8 \mathrm{~Gy}$ five times per week. After $45 \mathrm{~Gy}$ spinal cord was protected by using lead shielding. In right sided tumors, part of the liver was shielded after $30 \mathrm{~Gy}$. The mean dose to the small bowel was kept below 45 Gy and $0 \%$ of the volume was not allowed above $55 \mathrm{~Gy}$. The dose was prescribed at the patient's midplane at the field central axis. No attempt was done to include the entire surgical scar in the treated fields. MULTIDATA planning system was used for dose calculation. Radiotherapy was administered with megavoltage Elekta Linear accelerator machine dual energy using photon beams 6 and 10 MV. Acute and late toxic effects were graded according to EORTC/RTOG scale.

\subsection{Follow-Up}

The follow up protocol included physical examination every 3 - 4 months during the first 2 years, every $4-6$ months during the following 3 years and once yearly thereafter. Annual CT chest and abdomen was done during follow up or as per patient complaints.

Information about the disease and survival status was obtained from the clinical records. For any uncertainty, phone calls were made to patients by the cancer registry department at our institute; otherwise patients were considered lost to follow-up and censored at the date of their last visit for survival calculations.

\subsection{Statistical Analysis}

The duration of local control was measured from day 1 of treatment to the date of LR or last contact with the patient. Overall survival was measured from day 1 of diagnosis till death or the last follow up date.

Statistical package software system for windows was used for evaluation of the data. Descriptive statistics included values and percentages for quantitative data. Survival curves were obtained with the Kaplan-Meier method. The log-rank test was used to compare LR-FS and OS between groups, and a $p$ value of $\geq 0.05$ was considered statistically significant. Univariate analyses of the prognostic features were realized. Factors chosen for the final model for multivariable analysis were based on the elimination of non-significant factors on Univariate analysis. Multivariable regression analyses were performed to assess the independent impact of factors on the outcomes.

\section{Results}

The pathology reports showed that $89 \%$ of the patients were renal cell carcinoma and $11 \%$ were clear cell carcinoma and granular subtypes. Excised tumor sizes ranged from 7 to $23 \mathrm{~cm}$ in greatest diameter, with a median of $10 \mathrm{~cm}$. The pathological grade was G III and IV in $82 \%$ of patients. Fifty-five patients had right-sided tumor, and 39 patients had left-sided tumors. The follow up period ranges from 8 to 74 months with 59 months median value. Fifty six $(60 \%)$ patient who had received postoperative radiotherapy (PORT arm) compared to 38 $(40 \%)$ patients who did not receive PORT (non-PORT arm). Table 1 shows patients' characteristics with different prognostic factors in each group of patients. Sixty patients were male, and 34 patients were females. The age of the patients ranges from 29 to 71 years with median age 50 years (52-year in PORT arm and 45-year in non-PORT arm). Seventy one (75\%) patients had RCI (43 patients in PORT arm and 28 in non-PORT arms). Forty six (49\%) had RVI (31 patients in PORT arm and 15 patients in non-PORT arm). Thirty patients (32\%) had IVCI (19 patients in PORT arm and 11 in non-PORT arms). Sixty three $(67 \%)$ patients had $\mathrm{LN}+$ disease (40 patients in PORT arm and 23 in non-PORT arm). As shown in Table 2, 18 patients (19\%) developed LR and 30 patients (32\%) developed DM. Nine patients had both LR and DM. The LR documented in $10(26 \%)$ patients in non-PORT arm and in $8(14 \%)$ patients in PORT arm. At the time of analysis, 70 patients $(74 \%)$ were alive and 55 patients $(59 \%)$ were disease free.

Using the Kaplan Meier estimate, the 5y-OS and 5yLR-FS for all patients were $75 \% \pm 10 \%$ and $82 \% \pm 9 \%$ respectively. The prognostic factors studied include RCI, RVI, IVCI and LN+ in addition to PORT.

\subsection{Local Recurrence Free Survival}

The 5-year local recurrence free survival rate for PORT arm was $88 \% \pm 7 \%$ compared to $70 \% \pm 11 \%$ for the non- 
Table 1. Patients characteristics.

\begin{tabular}{|c|c|c|c|c|}
\hline Prognostic Factor & $\begin{array}{c}\text { Surgery + } \\
\text { PORT } \\
(\mathbf{N}=56)\end{array}$ & $\begin{array}{l}\text { Surgery } \\
(\mathbf{N}=38)\end{array}$ & $\begin{array}{c}\text { All } \\
(\mathrm{N}=94)\end{array}$ & $\mathbf{P}$ \\
\hline $\begin{array}{l}\text { Age in years } \\
\text { (median value) }\end{array}$ & 52 & 45 & 50 & NS \\
\hline $\begin{array}{l}\frac{\text { Sex }}{\text { Male }} \\
\text { Female }\end{array}$ & $\begin{array}{l}39(70 \%) \\
17(30 \%)\end{array}$ & $\begin{array}{l}21(55 \%) \\
17(45 \%)\end{array}$ & $\begin{array}{l}60(64 \%) \\
34(36 \%)\end{array}$ & NS \\
\hline $\begin{array}{c}\text { Renal Capsule } \\
\text { Invasion } \\
\text { No invasion }\end{array}$ & $\begin{array}{l}43(77 \%) \\
13(23 \%)\end{array}$ & $\begin{array}{l}28(74 \%) \\
10(26 \%)\end{array}$ & $\begin{array}{l}71(75 \%) \\
23(25 \%)\end{array}$ & S \\
\hline $\begin{array}{l}\frac{\text { Renal Vein }}{\text { Invasion }} \\
\text { No invasion }\end{array}$ & $\begin{array}{l}31(55 \%) \\
25(45 \%)\end{array}$ & $\begin{array}{l}15(40 \%) \\
23(60 \%)\end{array}$ & $\begin{array}{l}46(49 \%) \\
48(51 \%)\end{array}$ & NS \\
\hline $\begin{array}{c}\stackrel{\text { IVC }}{\text { Thrombus }} \\
\text { No thrombus }\end{array}$ & $\begin{array}{l}19(34 \%) \\
37(66 \%)\end{array}$ & $\begin{array}{l}11(29 \%) \\
27(71 \%)\end{array}$ & $\begin{array}{l}30(32 \%) \\
64(68 \%)\end{array}$ & NS \\
\hline $\begin{array}{l}\text { LN } \\
\text { Positive } \\
\text { Negative }\end{array}$ & $\begin{array}{l}40(71 \%) \\
16(29 \%)\end{array}$ & $\begin{array}{l}23(61 \%) \\
15(39 \%)\end{array}$ & $\begin{array}{l}63(67 \%) \\
31(33 \%)\end{array}$ & NS \\
\hline $\begin{array}{l}\text { Pathological Type } \\
\text { Renal cell ca } \\
\text { Clear cell carcinoma } \\
\text { Granular cell ca }\end{array}$ & $\begin{array}{l}53(95 \%) \\
2(3.5 \%) \\
1(1.5 \%)\end{array}$ & $\begin{array}{c}31(82 \%) \\
4(10 \%) \\
3(8 \%)\end{array}$ & $\begin{array}{c}84(89 \%) \\
6(6 \%) \\
4(4 \%)\end{array}$ & S \\
\hline $\begin{array}{c}\text { Pathological grade } \\
\text { G I, II } \\
\text { GIII, IV }\end{array}$ & $\begin{array}{c}7(12 \%) \\
49(88 \%)\end{array}$ & $\begin{array}{l}10(26 \%) \\
28(74 \%)\end{array}$ & $\begin{array}{l}17(18 \%) \\
71(82 \%)\end{array}$ & $\mathrm{S}$ \\
\hline
\end{tabular}

Table 2. Effect of post-operative radiotherapy on disease and survival status.

\begin{tabular}{cccc}
\hline \multirow{2}{*}{ Outcome } & \multirow{2}{*}{ Total No } & \multicolumn{2}{c}{ Patient groups } \\
\cline { 3 - 4 } & & Surgery + PORT & Surgery alone \\
\hline $\begin{array}{c}\text { Local Control } \\
\text { Recurrence }\end{array}$ & 18 & $8(14 \%)$ & $10(26 \%)$ \\
No Recurrence & 76 & $48(86 \%)$ & $28(74 \%)$ \\
Distant Metastasis & & & \\
\hline $\begin{array}{c}\text { Metastasis } \\
\text { No Metastasis }\end{array}$ & 30 & $16(29 \%)$ & $14(36 \%)$ \\
Overall Survival & 64 & $40(71 \%)$ & $24(64 \%)$ \\
\hline Alive & & & \\
Dead & 24 & $44(79 \%)$ & $26(68 \%)$ \\
& 24 & $12(21 \%)$ & $12(32 \%)$ \\
\hline
\end{tabular}

PORT arm with significant difference; $p$ value 0.05 (Figure 1).

The following parameters had a statistically significant influence on 5y LR-FS: renal capsule invasion and lymph node involvement. The probability of 5 -year LR-FS in case of renal capsule invasion were $71 \% \pm 11 \%$ compared to $88 \% \pm 8 \%$ for patients without RCI (p value 0.03 ). The 5y LR-FS for $\mathrm{LN}+$ patients was $73 \% \pm 8 \%$ and for node negative patients were $90 \% \pm 12 \%$; p value 0.04 .

The 5y-LR-FS was $78 \pm 8 \%$ in patients with IVCI vs. $83 \pm 10 \%$ in patients free from IVCI ( $p$ value 0.1 ). The renal vein invasion affected the 5y-LR-FS none significantly. The 5y LR-FS was $75 \% \pm 9 \%$ for patients with RVI vs. $85 \% \pm 13 \%$ for patients without RVI (p value $0.1)$.

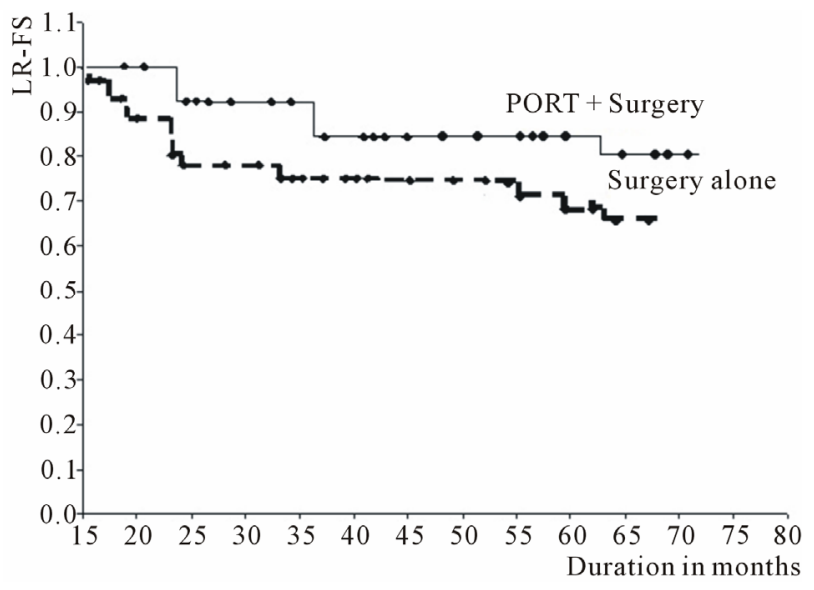

Figure 1. Local recurrence free survival difference in patients received post nephrectomy radiotherapy compared to patients performed surgery alone.

\subsection{Overall Survival Results}

The 5-year actuarial survival rate for PORT arm was $78 \% \pm 7 \%$ compared to $70 \% \pm 10 \%$ for the non-PORT arm. There was no significant difference observed in terms of 5-year overall survival between the groups with and without post-operative radiotherapy; $\mathrm{p}$ value 0.3 (Figure 2). As shown in Table 3, IVCI showed significant lower 5 y-OS $50 \% \pm 14 \%$ in comparison to $80 \% \pm$ $9 \%$ in patients with no inferior vena cava thrombosis; $p$ value 0.007 . The $\mathrm{LN}+$ was also highly predictive prognostic factor for OS $(79 \% \pm 8 \%$ in $\mathrm{LN}$ negative and $63 \%$ $\pm 12 \%$ in $\mathrm{LN}$ positive); $\mathrm{p}$ value 0.009 . On the other hand, $\mathrm{RCI}$ was not affecting $5 \mathrm{y}-\mathrm{OS}$ significantly with $\mathrm{p}$ value 0.6. Also, 5y-OS in the group of patients having RVI $(69 \% \pm 11 \%)$ was not significantly different compared to $78 \% \pm 7 \%$ in patients without RVI; $p$ value 0.08 . In multivariate analysis, none of the prognostic factors affected the 5y LR-FS significantly as shown in Table 3 . The $p$ value for the PORT is 0.07 with hazard ratio 0.8 and confidence interval ranges from 0.7 to 1.0. Analyzing the factors affecting overall survival, multivariate analysis showed that both IVCI and LN+ significantly affected $5 \mathrm{y}$ OS with $p$ value 0.2 and 0.1 respectively.

The acute treatment-related toxicities such as abdominal pain, nausea, vomiting and diarrhea were seen during radiotherapy. However generally, PORT was well tolerated. The serious events related to radiation were only in the form of intestinal obstruction which was in 2 patients out of 56 received PORT (3.5\%). Only 1 patient required surgical interference.

\section{Discussion}

We believe that OS in locally advanced RCC patients following RN is going to increase with the advent of targeted therapy in next decade, and we are going to see more loco-regional recurrences and for such patients 
Table 3. The effect of different prognostic factors on the 5-year local recurrence free survival and 5-year overall survival.

\begin{tabular}{|c|c|c|c|c|c|c|}
\hline \multirow[b]{2}{*}{ Prognostic factor } & \multicolumn{3}{|c|}{ Overall survival } & \multicolumn{3}{|c|}{ Local recurrence free survival } \\
\hline & $\begin{array}{l}5 \mathrm{y}-\mathrm{OS} \\
\% \pm \mathrm{S} D\end{array}$ & $\begin{array}{c}\text { Univariate analysis } \\
\mathrm{P} \text { value }\end{array}$ & $\begin{array}{c}\text { Multivariate analysis } \\
\mathrm{P} \text { value/HR }(\mathrm{CI})\end{array}$ & $\begin{array}{l}\text { 5y-LR-FS } \\
\% \pm \mathrm{SD}\end{array}$ & $\begin{array}{c}\text { Univariate analysis } \\
\mathrm{P} \text { value }\end{array}$ & $\begin{array}{c}\text { Multivariate analysis } \\
\text { P value/HR (CI) }\end{array}$ \\
\hline Radiotherapy & & & & & & $P=0.07$ \\
\hline Yes & $78 \% \pm 7 \%$ & 0.3 & Ns & $88 \% \pm 7 \%$ & 0.05 & $\mathrm{HR}=0.8$ \\
\hline No & $70 \% \pm 10 \%$ & & & $70 \% \pm 11 \%$ & & $(0.7-1.0)$ \\
\hline \multicolumn{7}{|l|}{ Renal Capsule } \\
\hline Invasion & $70 \% \pm 10 \%$ & & Ns & $71 \% \pm 11 \%$ & & \\
\hline No invasion & $77 \% \pm 11 \%$ & 0.6 & & $88 \pm 8 \%$ & 0.03 & ns \\
\hline IVC & & & $P=0.02$ & & & \multirow{3}{*}{ Ns } \\
\hline Thrombus & $50 \% \pm 14 \%$ & & $\mathrm{HR}=0.66$ & $78 \% \pm 8 \%$ & & \\
\hline No thrombus & $80 \% \pm 9 \%$ & 0.007 & $(0.02-1.4)$ & $83 \% \pm 10 \%$ & 0.1 & \\
\hline \multicolumn{7}{|l|}{ Renal Vein } \\
\hline Invasion & $69 \% \pm 11 \%$ & & Ns & $75 \% \pm 9 \%$ & & \multirow{2}{*}{ ns } \\
\hline No invasion & $78 \% \pm 7 \%$ & 0.08 & & $85 \% \pm 13 \%$ & 0.1 & \\
\hline$\underline{\mathbf{L N}}$ & & & $P=0.01$ & & & \multirow{4}{*}{ ns } \\
\hline Positive & $63 \% \pm 12 \%$ & & $\mathrm{HR}=0.3$ & $73 \% \pm 8 \%$ & & \\
\hline Negative & $79 \% \pm 8 \%$ & 0.009 & $(0.1-1.2)$ & $90 \% \pm 12 \%$ & 0.04 & \\
\hline All patients & $75 \% \pm 10 \%$ & & & $75 \% \pm 10 \%$ & & \\
\hline
\end{tabular}

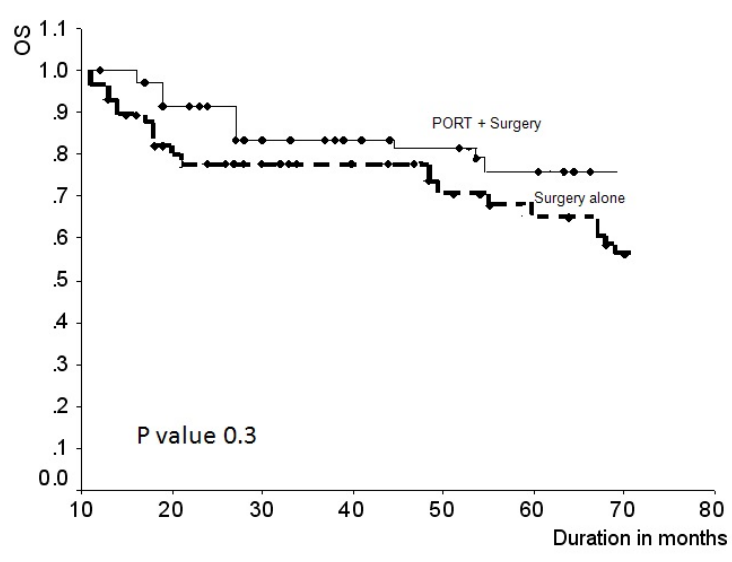

Figure 2. Effect of postoperative Radiation therapy on Overall survival.

PORT would be beneficial [13]. The retrospective trials have shown that radiotherapy improve the local control following radical nephrectomy. Cuneyt et al., retrospectively reviewed 40 patients [14]. Five-year OS rates were found $70 \%$ in the PORT group and $20 \%$ in the nonPORT group $(\mathrm{P}=0.1)$ and five-year DFS rates were found $66 \%$ in the PORT group and $16 \%$ in non-PORT and difference in both univariate and multivariate analyses $(\mathrm{P}=0.045$ and $\mathrm{P}=0.0007$, respectively $)$.

Rafla et al. reported the results of two retrospective studies, which showed that OS and DFS rates were better in patients who received PORT $[15,16]$. Stein et al., studied 56 patients with better OS and DFS in the group of patients received PORT. Five-year OS rates $50 \%$ in PORT and $40 \%$ in non-PORT groups respectively [8]. Safwat et al., reviewed 136 patients who underwent RN. DFS improved significantly by PORT in Univariate and multivariate analysis. Five-year cumulative risk of LR reduced from $38 \%$ to $22 \%$ (p value 0.014 ). However, in this study there was no difference in OS by adding PORT [7].

Makarewicz et al. also showed that the PORT reduced the LR rates from $15.8 \%$ to $8.8 \%$ in 114 patients with T3N0 RCC, but there was no significant effect on the OS rate [17]. However, Gez et al., retrospectively showed that PORT did not improve the LRC and was accompanied by mild to moderate adverse effects [18].

The prospective randomized trials which that tested the value of PORT and did not demonstrate an advantage in receiving radiotherapy were published by Finney [19] and Kjaer [11,12]. Finney et al. reported five-year OS rates of $36 \%$ in the PORT group and $47 \%$ in the nonPORT group. The LR rates were $7 \%$ for both groups.

The Copenhagen Renal Cancer Study Group (CRCSG) compared PORT 50Gy and non-PORT in patients having stage II or III renal cancer. There was no significant difference in DFS rates between the two groups. Forty four percent of the patients in the PORT group had radiationrelated gastrointestinal and hepatic complications [12].

The contradictory data in the literature between the retrospective and prospective studies regarding PORT was realized by recently published meta-analysis by Tunio et al. which included 7 randomized trials [13]. Seven hundred and thirty five patients were analyzed with pooled results from these trials showed a significant reduction of LR in patients treated with PORT $(\mathrm{P}$ value $0.0001)$. However, there was no difference in OS $(\mathrm{P}=$ $0.29)$ and DFS $(\mathrm{P}=0.14)$.

WE strongly believe that tailoring PORT for RCC patients may show a real benefit especially in patients with poor prognostic factors. In our study, we chose high risk patients (those with more than one poor prognostic factor; 
RVI, IVCI, LN+ and RCI) for evaluation of PORT retrospectively. Five-year LRC in our study is $82 \% \pm 9 \%$ which is higher than that reported by Safwat et al. [7] and similar to Aref series [4] and Gez et al. [18]. This is mainly due to better case selection in our series (inclusion of patients who underwent RN with lymphadenectomy and exclusion of patients with positive surgical margin or gross residual following surgery). The radiotherapy improved the local recurrence rate $(26 \%$ in nonPORT arm and $14 \%$ in PORT arm) however the DM was $29 \%$ and $39 \%$ in PORT and non-PORT patients respectively. These data is nearly similar to Aref and Makarewicz data. The isolated LRR were observed in $9(10 \%)$ patients only; six of them in the non-RT arm. Five-year LRC was worst in the group of patients having RCI and $\mathrm{LN}+$ with $\mathrm{P}$ values 0.03 , and 0.04 respectively. These findings are comparable to studies by Stein, Rafla and Finney data $[8,16,19]$.

The radiotherapy did not improve OS rates in our study and this is comparable to all retrospective and prospective studies [12-18]. Five-year OS in PORT arm was $78 \%$ as compared to $70 \%$ in non-PORT arm $(\mathrm{p}=0.3)$.

The univariate analysis showed that IVCI and LN+ affected the OS with $\mathrm{p}$ values 0.007 and 0.009 respectively. These findings were confirmed by multivariate analysis with $\mathrm{p}$ value 0.02 for the IVCI and 0.01 for $\mathrm{LN}+$. These results are comparable to the studies of Makarewicz et al. [17] and Safwat et al. [7]. The exclusion of the pathological types and the pathology grade was mainly due to unequal distribution of cases between the two treatment groups.

\section{Conclusion and Recommendation}

Our study showed the benefit of PORT in reducing local recurrence in locally advanced RCC. The overall survival was also better in irradiated patients, but the difference did not reach statistical significance. The high DM rate could justify the need for use of adjuvant targeted therapy in such high risk patients. As there are conflicting data in the literature regarding the value of PORT, multiinstitutional prospective randomized trials using modern radiotherapy techniques in addition to targeted therapy are necessary to evaluate the real role of PORT and improve survival in locally advanced RCC patients.

\section{REFERENCES}

[1] W. H. Chow, S. S. Devesa, J. L. Warren and J. F. Fraumeni Jr., "Rising Incidence of Renal Cell Cancer in the United States," JAMA, Vol. 281, No. 17, 1999, pp. 16281631. http://dx.doi.org/10.1001/jama.281.17.1628

[2] A. Jemal, R. Siegel, E. Ward, et al., "Cancer Statistics 2008," CA Cancer Journal for Clinicians, Vol. 58, No. 2, 2008, pp. 71-96. http://dx.doi.org/10.3322/CA.2007.0010
[3] J. Pantuck, A. Zisman and A. Bellderun, "The Changing Natural History of Renal Cell Carcinoma," The Journal of Urology, Vol. 166, No. 5, 2001, pp. 1611-1623. http://dx.doi.org/10.1016/S0022-5347(05)65640-6

[4] I. Aref, G. Bociek and D. Salhani, "Is Postoperative Radiotherapy for Renal Cell Carcinoma Justified?" Radiotherapy \& Oncology, Vol. 43, No. 2, 1997, pp. 155-157. http://dx.doi.org/10.1016/S0167-8140(97)01949-X

[5] A. P. Sene, R. F. T. Hunt, T. McMahon and R. N. P. Carol, "Renal Carcinoma in Patients Undergoing Nephrectomy: Analysis of Survival and Prognostic Factors," British Journal of Urology, Vol. 70, No. 2, 1992, pp. 125-134. http://dx.doi.org/10.1111/j.1464-410X.1992.tb15689.x

[6] R. A. Rabinovitch, M. J. Zelefsky, J. J. Gaynor and Z. Fuks, "Patterns of Failure Following Surgical Resection of Renal Cell Carcinoma: Implications for Adjuvant Local and Systemic Therapy," Journal of Clinical Oncology, Vol. 12, 1994, pp. 206-212.

[7] A. Safwat, T. Shouman and E. Hamada, "Postoperative Radiotherapy Improves Disease Free but Not Overall Survival in High Risk Cell Carcinoma Patients," Journal of the Egyptian National Cancer Institute, Vol. 12, 2000, pp. 17-22.

[8] M. Stein, A. Kuten, J. Halperin, N. M. Coachman, Y. Cohen and E. Robinson, "The Value of Postoperative in Renal Cell Cancer," Radiotherapy and Oncology, Vol. 24, No. 1, 1992, pp. 41-45. http://dx.doi.org/10.1016/0167-8140(92)90352-U

[9] M. Eilenberger, R. Kodyam and R. Seyess, "A Retrospective Study of the Results of Postoperative Radiotherapy of Hypernephroma," Radiobiologia, Radiotherapia (Berlin), Vol. 31, 1990, pp. 491-496.

[10] E. Scherer and C. Wirtz, "The Role of Postoperative Radiotherapy in the Treatment of Hypernephroid Carcinoma," Strahlentherapie und Onkologie, Vol. 164, 1988, pp. 371-385.

[11] M. Kjaer, P. L. Frederiksen and S. A. Engelholm, "Postoperative Radiotherapy in Stage II and III Renal Adenocarcinoma. A Randomized Trial by the Copenhagen Renal Cancer Study Group," International Journal of Radiation Oncology \& Biology \& Physics, Vol. 13, No. 5, 1987, pp. 665-672.

http://dx.doi.org/10.1016/0360-3016(87)90283-5

[12] M. Kjaer, P. Iversen, V. Hvidt, E. Bruun, P. Skaarup, H. J. Bech and P. L. Frederiksen, "A Randomized Trial of Postoperative Radiotherapy versus Observation in Stage II and III Renal Adenocarcinoma. A Study by the Copenhagen Renal Cancer Study Group," Scandinavian Journal of Urology, Vol. 21, No. 4, 1987, pp. 285-289. http://dx.doi.org/10.3109/00365598709180784

[13] M. A. Tunio, A. Hashmi and M. Rafi, "Need for New Trial to Evaluate PORT in Renal Cell Carcinoma: A Meta-Analysis of Randomized Controlled Trials," Annals of Oncology, Vol. 21, No. 9, 2010, pp. 1839-1845. http://dx.doi.org/10.1093/annonc/mdq028

[14] U. Cuneyt, A. Gorkem, F. Merdan, O. Kuzhan, L. Tahmaz and M. Beyzadeoglu, "The Value of Postoperative Radiotherapy in Renal Cell Carcinoma: A Single Institution Experience," Tumori, Vol. 92, 2006, pp. 202-206. 
[15] S. Rafla, "Renal Cell Carcinoma," Cancer, Vol. 25, 1970, pp. 26-40.

http://dx.doi.org/10.1002/1097-0142(197001)25:1<26::AI D-CNCR2820250106>3.0.CO;2-4

[16] S. Rafla and K. Parikh, "The Role of Adjuvant Radiotherapy in the Management of Renal Cell Carcinoma," In: N. Javadpour, Ed., Cancer of the Kidney, Thieme-Stratton, New York, 1984, p. 231.

[17] R. Makarewicz, M. Zarzycka, G. Kulinska and W. Windorbska, "The Value of Postoperative Radiotherapy in Advanced Renal Cell Cancer," Neoplasma, Vol. 45, 1998, pp. 380-383.

[18] E. Gez, M. Libes, R. Bar-Deroma, R. Rubinov, M. Stein and A. Kuten, "Postoperative Irradiation in Localized Renal Cell Carcinoma: The Rambam Medical Center Experience," Tumori, Vol. 88, 2002, pp. 500-502.

[19] R. Finney, “An Evaluation of Postoperative Radiotherapy in Hypernephroma Treatment-A Clinical Trial," Cancer, Vol. 32, No. 6, 1973, pp. 1332-1340. http://dx.doi.org/10.1002/1097-0142(197312)32:6<1332:: AID-CNCR2820320607>3.0.CO;2-E 